УДК 159.925

\title{
«СУГУБО ЖЕНСКАЯ ТЕМА» - ВНЕШНИЙ ОБЛИК
}

\author{
Лабунская Вера Александровна
}

Работа поддержана внутренним грантом Южного федерального университета, проект № 213.01-07-2014/15ПЧВГ «Угрозы национальной безопасности в условиях геополитической конкуренции и модели агрессивного и враждебного поведения детей и молодежи на Юге России»

Статья отражает основные тезисы сообщения, сделанного на круглом столе: «Роль женщин в истории психологии 20 века и в наше время», проведенного в рамках международной научно-практической конферениии «Сабина Николаевна Шпильрейн: ее личность и вклад в психоанализ, психологию развития, клиническую психологию» (7-8 ноября, 2015). В сообщении был сделан акцент на том, что С. Н. Шпильрейн можно отнести к тем исследователям, которые заложили основы «Women's Studies» в гуманитарных науках, в гендерных исследованиях, в психологии и психоанализе.

Изучение «женского опыта» женщинами-исследователями представлено обсуждением некоторых проблем, связанных с внешним обликом человека. Обращение к данной теме обусловлено не только тем, что она до настоящего времени в большинстве работ рассматривается как «женская тема», но и тем, что внешний облик самой С. Н. Шпильрейн «ускользает» от исследователей, его оченки являются противоречивыми, и сама С. Н. Шпильрейн «находит себя малопривлекательной», о чем она пишет в своем дневнике, «сомневается в своих женских достоинствах».

Жизнь С. Н. Шпильрейн - это жизнь человека, которая конструируется и находится под «чужим взглядом», что ставит задачу рассмотрения женского внешнего облика, находящегося в поле зрения «маскулинного взгляда», как одну из тем женских исследований. В сообщении данная тема раскрывалась на основе ряда исследований, которые можно рассматривать как "женские исследования», обращенные к изучению женшинами таких феноменов, сопряженных с внешним обликом, как переживание оценок внешнего облика, обеспокоенность внешним обликом. С точки зрения этих исследований могут быть рассмотрены некоторые аспекты биографии С. Н. Шпильрейн.

Ключевые слова: женские исследования, женский опыт, внешний облик, отношение, переживание, оценка, преобразование, гендерные отношения, самопрезентация, со-бытие. 


\section{Введение}

В многочисленных словарных статьях, публикациях [напр., 41, 42] отмечается, что к «Women's Studies» можно отнести любые исследования, в которых рассматриваются так называемые «женские темы», преимущественно женщинами - практиками и теоретиками. Особое внимание в этих работах уделяется проблеме дискриминации женщин, их социальному статусу, системе их отношений, а в контексте гендерного подхода акцент делается на вопросах взаимоотношений между мужчинами и женщинами, подчеркивается влияние «мужского взгляда» на самовосприятие женщин, на оценку ими своих достижений, в конце концов, на их удовлетворенность жизнью.

В центре «женских исследований» стоит задача определения специфики женского опыта, женских практик. Если посмотреть на научное творчество, на практическую деятельность С. Н. Шпильрейн с точки зрения «Women's Studies», то можно сказать о том, что ее «женский опыт», ее «женские практики» отрефлексированы ею самой (см. дневники С. Н. Шпильрейн), а также стали предметом аналитической деятельности большого отряда ученых, не только женщин. Даже беглое знакомство с имеющимися отечественными работами и переведенными на русский язык зарубежными исследованиями [32, 39, 40], посвященными различным аспектам жизнедеятельности С. Н. Шпильрейн, позволяет заключить, что она оказалась под пристальным «мужским взглядом», что ее «женский опыт» включает рефлексию гендерных отношений, что в их рамках у нее появляются сомнения относительно своей привлекательности для противоположного пола, относительно своего внешнего облика.

В целом, как следует из ее дневников, С. Н. Шпильрейн «находит себя малопривлекательной». Одновременно, 3. Фрейд, познакомившись с ней, пишет своему ученику К. Юнгу о том, что встретил «милую девушку». Интересны воспоминания тех людей, которые в Женеве учились в одно время с С. Н. Шпильрейн и оставили воспоминания о ее круге: «...группа ростовских девушек... значительно отличалась от обычных студенток-евреек швейцарских университетов того времени по внешности, манерам, взглядам. Они были гораздо привлекательнее, чем их ровесницы из черты оседлости... Студенческое общественное мнение было против ростовчанок, но те не обращали внимания на вражду... община Ростова была сравнительно богата... Поэтому и составляли ростовские девушки контраст с большинством еврейских студенток Женевы, которые чаще всего выглядели нервными, разочарованными, чахлыми и голодными» [приводится по 39, с. 160]. Вместе с этим, в дневниках С. Н. Шпильрейн исследователи обнаруживают негативный взгляд сокурсников, как мужчин, так и женщин, 
друг на друга. Неприятные прозвища фиксировали некоторые особенности внешнего облика.

Таким образом, с момента приобщения С. Н. Шпильрейн к правилам студенческого со-бытия, она попадает в поле враждебных отношений, актуализированных инаковостью ее внешнего облика, поведения, привлекательностью, а также своеобразием взаимоотношений между мужчинами и женщинами - студентами, обучающимися в швейцарских институтах. Несмотря на то, что вышеприведенные воспоминания относятся к началу XX в., они еще раз подчеркивают, что потребность в самопрезентации, в предъявлении себя другому и самому себе является культурной потребностью, функционирование которой не имеет временных границ, еще раз указывают на устойчивость форм самопредъявления и его важнейшие функции: определение ситуации для себя и присутствующих, контроль за их поведением, создание благоприятного впечатления о себе, достижение наибольшей выгоды от взаимодействия [8]. Но самопрезентация - это не только управление впечатлениями других людей, но и один из способов получения знаний субъекта о себе, об отношении к самому себе. Именно данная функция представляет особый интерес в связи с рассмотрением «женского опыта», «женских практик», гендерных отношений, т. к. выдвигает на передний план вопрос о субъектности «женских самопрезентаций», о включенности самопрезентации, осмысления впечатления для себя и других в качестве важнейшей, значимой составляющей в событийную картину мира человека.

Следует отметить тот факт, что внешний облик человека всегда находится в поле оценок и самооценок. Они отражают отношение к человеку. Известен такой факт из биографии С. Н. Шпильрейн, который демонстрирует восприятие и оценку ее внешнего облика на определенном этапе жизненного пути. Падчерица С. Н. Шпильрейн вспоминает: «Одевалась она только в то, что кто-то ей давал. Она была похожа на маленькую старушку, хотя она была не такой старой. Она была согбенная, в какой-то юбке до земли, старой, черной. На ней были ботики на застежечках, теперь их называют "прощай, молодость". Я думаю, что привезла она их из Берлина. Так одевалась моя бабушка. Было видно, что она сломлена жизнью» [приводится по 39, с. 210]. В памяти подруг дочери С. Н. Шпильрейн она тоже осталась худой, маленькой, некрасивой седой старушкой, обычно сидевшей в углу дивана [40]. Данная оценка внешнего облика С. Н. Шпильрейн представлена в интервью 1990 г., которое дала падчерица С. Н. Шпильрейн; оценка относится к женщине 52 лет, но отражает то, что зафиксировала девочка подросткового возраста. Она же в интервью 1990 г. сообщает, что дочь С. Н. Шпильрейн - Рената, приехавшая на празднование Нового 
года, «...была красивая, артистичная, в вечернем платье» [приводится по 40]. Следовательно, конструирование внешнего облика С. Н. Шпильрейн не столько связано с временем жизни, сколько с отношением к жизни, с мерой удовлетворенности ей.

Таким образом, «женский опыт» С. Н. Шпильрейн, связанный с отношением к внешнему облику, ее жизнь, проходящая под пристальным во многом «чужим, мужским взглядом», ставит перед современными «Women's Studies» задачу изучения внешнего облика, включенного в событие женщин.

\section{Внешний облик и его влияние на жизнь человека, оценку его лич- ностных свойств}

Психология внешнего облика на протяжении всей истории ее развития обращается к изучению отношения, восприятия внешнего облика, факторов определения его привлекательности $[2,5,15,23,24,31,36$, $38,53]$. В последнее время все чаще появляются исследования, в которых рассматриваются взаимосвязи между «внешним обликом и субъективным благополучием человека» [46]. N. Gupta, N. Etcoff и др. в процессе лонгитюдного исследования установили, что мера привлекательности внешнего облика позитивно коррелирует с показателями субъективного благополучия, с оценками качества жизни и имеет обратно пропорциональные связи с проявлениями негативных состояний и депрессий. Авторы данной работы уверены в том, что привлекательность внешнего облика, влияя на психические состояния человека, оказывает воздействие на различные характеристики человеческой жизни. С выводами приведенной выше работы согласуются данные исследования, выполненного Е. В. Белугиной [2], в котором она зафиксировала феномен влияния самоотношения к внешнему облику на удовлетворенность жизнью, на оценку различных этапов жизненного пути. Е. В. Белугина показала, что чем выше самооценка внешнего облика, чем выше удовлетворенность им, тем выше удовлетворенность жизнью.

Мера привлекательности внешнего облика влияет на оценку здоровья человека, на приписывание ему позитивных/негативных качеств личности [51]. Из общего потока работ можно выделить те, в которых рассматривается влияние гендера лица на оценку его привлекательности [48], а также исследования [49], в которых изучалось влияние привлекательности одного из партнеров на оценку аттрактивности другого партнера противоположного пола, или работы, в которых ставилась задача рассмотреть внешний облик как предиктор оценки добросовестности академической успеваемости студентов [45]. Весьма важными являются работы, в которых 
изучаются причины иллюзий партнеров романтических отношений, связанных с привлекательностью внешнего облика [43].

Продолжаются исследования, в которых рассматривается связь между внешним обликом, отдельными его компонентами (позы, выражения лица) и оценками качеств личности [50]. К ним примыкают работы, в которых оценивался интеллект и физическая привлекательность [47]. В исследовании S. Kanazawa в очередной раз доказывается, что существует корреляция между оценками умственных способностей и физической привлекательностью, интенсивность которой может быть опосредована принадлежностью субъекта оценки к определенной этнокультурной и гендерной группе. Результаты указанного исследования говорят о том, что связи между интеллектом и физической привлекательностью интенсивнее, если в качестве объекта оценки выступают мужчины. Известный исследователь в области психологии внешнего облика L. A. Zebrowitz с коллегами [53] рассмотрел несколько подходов к интерпретации взаимосвязи между «выглядеть интеллектуально и выглядеть привлекательно», одним из них является социально-психологическое объяснение, опирающееся на феномен сбывающегося пророчества.

В психологии внешнего облика уделяется внимание таким сложным вопросам, как проявление во внешнем облике нарциссизма. Авторы исследования [52], ставя данную проблему, указывают на то, что люди, склонные к нарциссизму, озабочены своим внешним обликом, но несмотря на этот факт, мы имеем мало сведений о том, как проявляется нарциссизм во внешнем облике. В своей работе они отмечают различные особенности внешнего облика, свойственные людям с нарциссическими наклонностями, и приводят данные, которые свидетельствуют о том, что внешность отражает личностные особенности нарцисса, его озабоченность внешним обликом, его желание быть в центре внимания, что влияет на его статус.

Проблема обеспокоенности, озабоченности внешним обликом ставится также в связи с изучением людей, которые имеют очевидные деформации внешнего облика, а также в связи с обнаружением феномена «тотальной неудовлетворенности внешним обликом», независимо от негативных изменений внешнего облика [31, 36]. О феномене телесного перфекционизма как социокультурной патологии пишет В. В. Парамонова [27]. К этой проблеме примыкает вопрос о переживаниях людей, внешний облик которых получает отрицательные оценки $[1,13,17,19]$. В исследованиях последнего времени подчеркивается, что оценки внешнего облика могут указывать на скрытую дискриминацию человека $[5,18,28]$, приводить к поиску способов, приемов снижения фрустрации, вызванной негативными оценками внешнего облика $[7,16,35]$. 
Изучение проблемы восприятия человеком своего собственного внешнего облика, отраженного Другими, восприятия «впечатлений», которые порождает внешний облик и которые представлены в оценках Другого, а также переживания, связанного с «Зеркальным Я», приближает к исследованию бытийных и бытовых аспектов жизни человека. Из разнообразных работ [37], касающихся изучения вопросов оценивания Другим, известно, что сам процесс оценивания и реакция на него зависят от сочетания большого количества факторов, среди которых одно из первых мест занимает личность субъекта оценки и ее место в системе взаимоотношений. Фундаментальным является вывод о том, что ситуация оценивания одного человека другим приводит к повышению уровня тревожности, к актуализации различных видов переживаний [22].

Одним из социально-перцептивных эффектов, связанных с «Зеркальным Я», является переживание оценок Другими внешнего облика, которые обусловлены взаимовлиянием макро- и микросоциальных факторов, приводящих к повышению уровня тревоги, обеспокоенности, агрессии. Среди этих факторов важное место занимают ролевая позиция субъекта негативного оценивания внешнего облика, степень его значимости для человека, внешний облик которого подвергается критике. Особую роль в снижении уровня фрустрации играет выраженность различных компонентов жизнестойкости, т. к. они «препятствуют возникновению внутреннего напряжения в стрессовых ситуациях», приводят к снижению значимости стрессогенных факторов [21], в качестве которых выступают негативные оценки внешнего облика различными партнерами по взаимодействию.

Данные выполненного нами исследования $[17,19]$ указывают на то, что чем старше человек, тем ниже уровень фрустрации, выраженности агрессии в связи с негативными оценками его внешнего облика «значимыми другими». Уровень негативных переживаний (фрустрация), агрессия, возникшие в результате негативных оценок внешнего облика «значимыми другими», «деловыми партнерами», лицами своего пола, взаимосвязан со стремлением изменять свой внешний облик, выбирая различные практики, в том числе эстетическую хирургию. Иными словами, негативная оценка именно этих партнеров выступает в роли мотивационного фактора, что можно считать одним из социально-перцептивных эффектов негативного оценивания внешнего облика Другими. Кроме этого результата, наше исследование показало, что между общим уровнем фрустрации, негативным переживанием и выраженностью такого компонента жизнестойкости, как принятие риска, существуют высоко значимые обратно пропорциональные взаимосвязи. На наш взгляд, учитывая трактовку этого компонента жизнестойкости создателями теста (показатель убежденности в том, что 
все происходящее приносит ценный жизненный опыт [21]), можно предположить, что совладание с негативными переживаниями оценок внешнего облика - это переосмысление «Зеркального Я», ведущее к преобразованию внешнего облика и приобретению иного жизненного опыта.

\section{Заключение}

Следует отметить, что каждое из направлений исследований, которые мы объединяем в одно под названием «социокультурные и социальнопсихологические функции внешнего облика в жизни человека», в качестве главного эмпирического объекта, как правило, выбирает женщин различного возраста, заявляя тем самым, что рассматриваемые темы изучения внешнего облика относятся в большей мере к женщинам. Авторами приведенных работ являются как женщины, так и мужчины. К сожалению, отсутствует достоверная статистика, кто чаще - мужчины или женщины - обращается к исследованию «сугубо женской темы - внешнего облика», но можно не сомневаться в том, что все наиболее важные вопросы, касающиеся включенности внешнего облика в жизнедеятельность человека, были сформулированы мужчинами-исследователями. Иными словами, «женская тема - внешний облик» по-прежнему остается в зарубежной и в отечественной психологии тем предметом изучения, который недостаточно представлен в рамках «Women's Studies», когда на исследовании женского опыта сосредотачиваются женщины-ученые. Следовательно, одной из задач современных исследований роли внешнего облика в жизни женщин может стать задача осмысления женщинами-учеными той темы, которая обозначена мужчинами как «сугубо женская тема».

Вместе с этим, можно указать на ряд публикаций $[4,10,11,12,14,25$, $30,33,38]$, которые демонстрируют понимание женщинами-исследователями роли внешнего облика в современном социальном пространстве. Так, в работе Н. Вульф [6] представлен «женский взгляд» на проблему женской красоты. Она пишет о том, что созданный «миф» о значимости женской красоты - это попытка укрепить власть над женщинами, усилить контроль общества над жизнью женщин. С точки зрения Н. Вульф, женские движения добились «принятия законов, запрещающих дискриминацию по признаку гендерной принадлежности в профессиональной сфере, но, как прямое следствие этого... незамедлительно появилось прецедентное право, которое превратило в общепринятую практику при приеме на работу дискриминацию женщин по признаку внешности» [6, с. 30]. Т. В. Селизова [34], рассматривая «концептуальный признак внешность» в оценке образа женщины на материале романа французского автора Даниэля Пеннака, утверждает, что анализ различных характеристик внешнего облика женщин 
указывает на отношение автора к женщине. Она подчеркивает, что с точки зрения мужчины, «привлекательная женщина должна пробуждать интерес своими яркими внешними данными: приятная округлость ее форм, мягкость, женственность, кокетство, пикантность, умение и желание нравиться, свойственные настоящим женщинам. Непривлекательная внешность для мужского пола заключается в чрезмерной худобе, пассивности, физической неактивности» [34, с. 95].

Специалист по гендерной психологии М. Палуди [26] представила обзор исследований, в которых ставилась задача выявить влияние образов, сконструированных СМИ и навязываемых ими, на удовлетворенность женщин своим внешним обликом. Она попыталась ответить на вопрос: «Зачем женщины наносят себе вред, пытаясь завоевать одобрение общества?». Имеются в виду различные практики преобразования своего внешнего облика. В качестве ответа на поставленный вопрос М. Палуди приводит рассуждения ряда авторов, обобщение которых позволяет ей ответить на поставленный вопрос, выделив взаимосвязь между успехом и женственностью, презентируемую во внешнем облике. Кроме этого ответа она солидарна с выводами Сьюзан Браунмиллер, которая полагает, что «...внешность - основное оружие в соперничестве женщин. Внешность, а не успех демонстрирует достоинство женщины и ее привлекательность для мужчин...» [приводится по 26, с. 165].

О том, что привлекательная, красивая женщина находится под пристальным взглядом не только мужчин, но и женщин, свидетельствуют данные исследования Д. В. Погонцевой [29], которая изучала представления женщин о красивой женщине. Большинство участниц ее исследования считали красивую женщину более счастливой, полагали, что ей завидуют окружающие, что красивые женщины в большей степени, чем другие переживают из-за своего внешнего облика.

С точки зрения представителей гендерных исследований $[9,10]$, стремление женщин следовать неким эталонам красоты лишает их индивидуальности, ведет к актуализации экзистенциальных проблем, переживаний, порожденных дискриминацией определенных социально-возрастных групп.

Завершая статью, необходимо еще раз подчеркнуть, что факты из биографии С. Н. Шпильрейн, особенности ее поведения, отношений и взаимоотношений с другими людьми - это определенный «женский опыт», который может быть интерпретирован сквозь призму взаимосвязей между внешним обликом человека и качеством его жизни. Такой взгляд предполагает проведение исследований, в которых бы затрагивалась проблема влияния внешнего облика на со-бытие женщин, изучался бы «женский опыт», связанный с такими явлениями, как красивая/некрасивая, аттрактивная, 
ставилась бы задача понимания статуса женщины, внешний облик которой постоянно находится в поле зрения «маскулинного взгляда». Жизнь и судьба С. Н. Шпильрейн, отрефлексированная с различных позиций, может быть также рассмотрена в рамках поставленных задач.

\section{Литература}

1. Батлер Д. Гендерное беспокойство // Антология гендерной теории: Сб. переводов / Составление, коммент. Е. И. Гаповой, А. Р. Усмановой. Минск: Пропилеи, 2000. - С. 297-346.

2. Белугина Е. В. Внешний облик как культурно-исторический феномен // Российский психологический журнал. - 2008. - № 3. - С. 58-65.

3. Белугина E. B. Отношение к своему внешнему облику в период середины жизни: автореф. дисс. ... канд. психол. наук. - Ростов н/Д, 2003.

4. Бондаренко И. В. Личностная обусловленность оформления внешнего облика // Вестник Томского государственного университета. - 2010. № 332. - С. 155-157.

5. Вигарелло Ж. Эталоны привлекательности в современной культуре // Искусство привлекательности. История телесной красоты от Ренессанса до наших дней. - М.: Новое литературное обозрение, 2013. - С. 303-310.

6. Вульф Н. Миф о красоте: Стереотипы против женщин. - М.: Альпина Нон-фикшн, 2013. - С. 22-35.

7. Гилман Л. С. Этнические вопросы в эстетической хирургии // Формула красоты. Чужое лицо / Под ред. А. Ташен. - М.: АСТ, Астрель, 2006. С. 11-139.

8. Гофман И. Представление себя другим в повседневной жизни. М.: КАНОН-пресс-Ц, Кучково поле, 2000.

9. Гросс Э. Изменяя очертания тела // Введение в гендерные исследования. - Харьков: Изд-во ХЦГИ; СПб.: Алетейя, 2001. - С. 529-626.

10. Дворкин А. Гиноцид, или Китайское бинтование ног // Женская солидарность: пособие для женщин и мужчин. - М.: Пропилеи, 2002. - С. 10-25.

11. Досина Н. В., Кошкина А. О. Внешность женщины как фактор социальных отношений. - 2010. - № 1. - С. 62-77.

12. Иванова Е. Н. Женщина в российской политической карикатуре // Женщина в российском обществе. - 2013. - № 3. - С. 66-78.

13. Килборн Б. Исчезающие люди: стыд и внешний облик. - М.: КогитоЦентр, 2007.

14. Клюкина Ю. В. Гендерные стереотипы внешнего портрета человека: автореф. дисс. ... канд. филол. наук. - Тамбов, 2011.

15. Лабунская В. А. «Видимый человек» как социально-психологический феномен // Социальная психология и общество. - 2010. - № 1. - С. 26-39. 
16. Лабунская В. А. Проблема удовлетворенности внешним обликом: субъектный подход // Научно-методический электронный журнал «Концепт». - 2014. - Т. 20. - С. 3856-3860.

17. Лабунская В. А. Социально-перцептивные эффекты со-бытия: «Зеркальное Я», переживание и совладание // От Истоков к современности: 130 лет организации психологического общества при Московском университете: Сборник материалов юбилейной конференции: В 5 томах. Том 3 / Отв. ред. Д. Б. Богоявленская. - М.: Когито-Центр, 2015. - С. 139-141.

18. Лабунская В. А., Бзезян А. А. Особенности оценивания различных компонентов этнокультурных типов внешнего облика как проявление дискриминационного отношения // Российский психологический журнал. - 2013. - № 3. - С. 37-43.

19. Лабунская В. А., Самаева Е. С. Негативная оценка в процессе общения внешнего облика как фактор фрустрации // Международная конференция «Психология общения и доверия: теория и практика». - М.: Изд-во МГУ, изд-во Университета РАО. - С. 152-155.

20. Лейбин В. М. Сабина Шпильрейн: Между молотом и наковальней. М.: Когито-Центр, 2008.

21. Леонтьев Д. А., Рассказова Е. И. Тест жизнестойкости. - М.: Смысл, 2006.

22. Майерс Д. Социальное познание и тревога // Социальная психология. СПб.: Питер, 1997. - С. 211-213.

23. Майерс Д. Физическая привлекательность // Социальная психология. СПб.: Питер, 1997. - Гл. 13. - С. 542-550.

24. Мещеряков Б. Г., Ющенкова Д. В. Глаза как предикторы воспринимаемой физической аттрактивности женских лиц // Культурно-историческая психология. - 2006. - № 1. - С. 48-55.

25. МихельД. Ужасные отражения материнского тела: примеры гендерных политик на Западе в современную эпоху // Гендерные исследования. 2000. - № 4. - С. 203-226.

26. Палуди М. Влияние женских образов в СМИ на удовлетворенность женщин собственным телом // Психология женщины. - СПб.: ПраймEВРОЗНАК, 2003. - С. 161-167.

27. Парамонова В. В. Феномен телесного перфекционизма как социокультурная патология // Культурно-историческая психология. - 2009. № 3. - С. 34-41.

28. Погонцева Д. В. Виды дискриминации по внешнему облику// Психология и психотехника. - 2013. - № 9. - С. 858-861.

29. Погонцева Д. В. Красивая женщина: социально-демографический анализ представлений // Социальная психология и общество. - 2011. - № 1. С. 73-82. 
30. Пушкарева Н. Л. Женщины-ученые в постсоветском фольклоре // Вестник РГНФ. - 2007. - № 1. - С. 30-40.

31. Рамси Н., Харкорт Д. Психология внешности. - СПб.: Питер, 2009.

32. Рихебехер С. Сабина Шпильрейн: «Почти жестокая любовь к науке». Биография (пер. с нем. К. А. Петросян, И. Е. Попова). - Ростов н/Д: Феникс, 2007.

33. Рягузова Е. В. Социокультурная обусловленность восприятия внешности незнакомого другого // Изв. Сарат. ун-та. Нов. сер. Акмеология образования. Психология развития. - 2015. - Т. 4. - Вып. 2 (14). - С. 167-169.

34. Селизова Т. В. Концептуальный признак внешность в оценке образа женщины // Вестник Ленинградского государственного университета им. А. С. Пушкина. - 2011. - Т. 7. - № 4. - С. 85-95.

35. Сластенина В. В. Взаимосвязь психологических особенностей и межличностных отношений женщин, прибегающих к услугам эстетической хирургии: автореф. дисс. ... канд. психол. наук. - Самара, 2007.

36. Суэми В., Фернхейм А. Психология красоты и привлекательности. - СПб.: Питер, 2009.

37. Шкуратова И. П. Структура социально-перцептивных оценок // Эмоциональные и познавательные характеристики общения. - Ростов н/Д.: Изд-во РГУ, 1990. - С. 6-13.

38. Шляхова С. С. Русская красота триста лет спустя: этнические авто- и гетеростереотипы в рекламе. Часть І. Автостереотипы; Часть II. Гетеростереотипы // Медиаскоп. - 2015. - Вып. 4 // URL: http://www.mediascope. $\mathrm{ru} / \mathrm{node} / 1862$

39. Эткинд А. Чистая игра с русской девушкой: Сабина Шпильрейн // Эрос Невозможного. - СПб.: МЕДУЗА, 1993. - Глава V. - С. 159-212.

40. Якушев И. Б. История астероида (Сабина Шпильрейн) // Клиническая и медицинская психология: исследования, обучение, практика: электрон. науч. журн. - 2015. - № 2 (8) // URL: http://medpsy.ru/climp

41. Ярская-Смирнова Е. Р. Женские и гендерные исследования за рубежом // Словарь гендерных терминов (Под ред. А. А. Денисовой). Региональная общественная организация «Восток-Запад: Женские Инновационные Проекты». - М.: Информация XXI век, 2002. - С. 100-103.

42. Ярская-Смирнова Е. Р. Истоки и методы гендерных исследований // Одежда для Адама и Евы: Очерки гендерных исследований. - М.: Издво ИНИОН РАН; Саратов: Изд-во Гос. тех. ун-та, Центра соц. политики и гендерных исслед. - М., 2001. - Ч. 1. - С. 7-92.

43. Bareld D. P., Dijkstra H., Koudenburg P. \& Swami V. An assessment of positive illusions of the physical attractiveness of romantic // Journal of Social and Personal Relationships. - 2011. - V. 28. - pp. 706-719. doi:10.1177/0265407510385492 
44. Bleske-Rechek A., Kolb C. M., Stern A. St., Quigley K., Nelson L. A. Face and Body: Independent Predictors of Women's Attractiveness // Archives of Sexual Behavior. - 2014. - V. 43. - Issue 7. - pp. 1355-1365.

45. Di Domenico S. I., Quitasol M. N., Fournier M. A. Ratings of Conscientiousness from Physical Appearance Predict Undergraduate Academic Performance // Journal of Nonverbal Behavior. - 2015. - V. 39. - Issue 4. - pp. 339-353.

46. Gupta N., Etcoff N. L., Jaeger M. Beauty in Mind: The Effects of Physical Attractiveness on Psychological Well-Being and Distress // Journal of Happiness Studies. - 2015. - pp. 1-13 // URL: http://link.springer.com/ article/10.1007\%2Fs10902-015-9644-6

47. Kanazawa S. Intelligence and physical attractiveness // Intelligence. - 2011. V. 3. - pp. 7-14. doi:10.1016/j.intell.2010.11.003

48. Kondo A., Takahashi K., Watanabe K. Influence of gender membership on sequential decisions of face attractiveness // Attention, Perception \& Psychophysics. - 2013. - V. 75. - Issue 7. - pp. 1347-1352.

49. Little A. C., Caldwell Ch. A., Jones B. C., DeBruine L. M. Effects of Partner Beauty on Opposite-Sex Attractiveness Judgments // Archives of Sexual Behavior. 2011. - V. 40. - Issue 6. - pp. 1119-1127.

50. Naumann L. P., Vazire S., Rentfrow P. J. \& Gosling S. D. Personality judgments based on physical appearance // Personality and Social Psychology Bulletin. 2009. - V. 35. - pp. 1661-1671. doi:10.1177/0146167209346309

51. Nikitina E. Estimations of Health and Personal Traits Attribution to Attractive and Unattractive Face Stimuli // Materials of the 5th International Conference on Interdisciplinary Social Sciences // URL: http://i10.cgpublisher.com/ proposals/1412

52. Vazire S., Naumann L. P., Rentfrow P. J. \& Gosling S. D. Portrait of a narcissist: Manifestations of narcissism in physical appearance // Journal of Research in Personality. - 2002. - V. 42. - pp. 1439-1447. doi:10.1016/j.jrp.2008.06.007

53. Zebrowitz L. A., Hall J. A., Murphy N. A. \& Rhodes G. Looking smart and looking good: Facial cues to intelligence and their origins // Personality and Social Psychology Bulletin. - 2002. - V. 28. - pp. 238-249. doi:10.1177/0146167202282009 